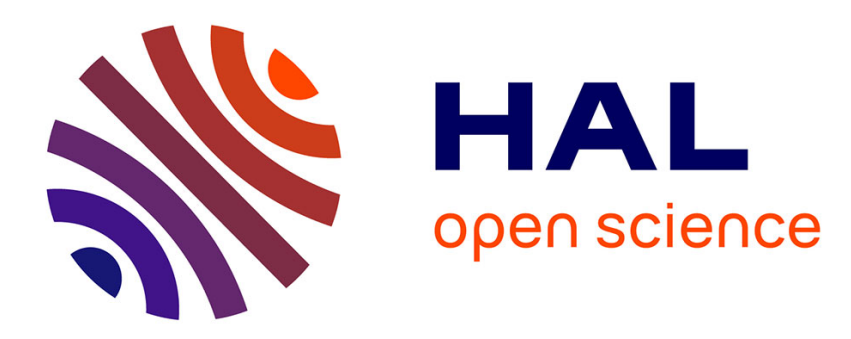

\title{
Fatigue initiation in heterogeneous brittle materials
}

François Hild, Stéphane Roux

\section{To cite this version:}

François Hild, Stéphane Roux. Fatigue initiation in heterogeneous brittle materials. Mechanics Research Communications, 1991, 18 (6), pp.409-414. 10.1016/0093-6413(91)90054-Z . hal-01635992

\section{HAL Id: hal-01635992 \\ https://hal.science/hal-01635992}

Submitted on 30 Oct 2019

HAL is a multi-disciplinary open access archive for the deposit and dissemination of scientific research documents, whether they are published or not. The documents may come from teaching and research institutions in France or abroad, or from public or private research centers.
L'archive ouverte pluridisciplinaire HAL, est destinée au dépôt et à la diffusion de documents scientifiques de niveau recherche, publiés ou non, émanant des établissements d'enseignement et de recherche français ou étrangers, des laboratoires publics ou privés. 


\section{FATIGUE INITIATION IN HETEROGENEOUS BRITTLE MATERIALS}

\author{
François HILD \\ Laboratoire de Mécanique et Technologie \\ Ecole Normale Supérieure de Cachan \\ 61 Avenue du Président Wilson, \\ 94235 CACHAN Cedex, France
}

\author{
Stéphane ROUX \\ Centre d'Enseignement et de Recherche en Analyse des \\ Matériaux, Ecole Nationale des Ponts et Chaussées \\ 1 Avenue Montaigne, Central IV, \\ 93167 Noisy le Grand Cedex, France
}

\section{Introduction}

The fatigue process can be schematically divided into an initiation stage and the propagation period. In this paper, we consider brittle materials where only the initiation phase needs to be studied, since the propagation is always unstable. We suppose that the initiation is due to some initial randomly distributed defects that grow according to a generalized Paris' law and become critical for a given number of cycles and for a given load level (characterized by a maximum equivalent stress $\sigma$ over a cycle). The purpose of this paper is to present a statistical approach of the initiation stage in fatigue derived from a unified framework of the failure probability in the case of monotonic and cyclic loadings. We will show in particular that the iso-probability curves in a Wohler diagram, have a shape which is independent of the initial statistical distribution of defects. Applications of this study are to be found in the case of engineering ceramics.

The first section of this paper is devoted to the introduction of our model for the evolution of an initial defect subjected to a cyclic loading with a uniform stress. In the second section, this mesoscopic model is applied to the analysis of a structure $\Omega$ of volume V subjected to any stress field and divided into a large number of representative volume element $\mathrm{V}_{0}$.

\section{Mesoscopic model: Defect Distribution and its Evolution}

Initial heterogeneities in the material are modelled by randomly distributed defects only characterized by their size, $a$. No restriction is assumed on the form of the initial distribution of defects, $f(a)$. In the case of cyclic loadings, the defects grow. We assume that this evolution is given by a generalized form of Paris' law : 


$$
\begin{array}{ll}
\frac{\mathrm{d} a}{\mathrm{dN}}=0 & \text { if } a<a_{\mathrm{th}} \\
\frac{\mathrm{d} a}{\mathrm{dN}}=C \sigma^{\mathrm{n}}\left(\sqrt{a} \cdot \sqrt{a_{\mathrm{th}}}\right)^{\mathrm{m}} & \text { if } a>a_{\mathrm{th}}
\end{array}
$$

where $\sigma$ is a maximum equivalent stress over a cycle (e.g. the maximum value over a cycle of the principal tensile stress for ceramics), $a$ is the size of defect (for instance the length of a crack in a two dimensional problem or the radius of a penny-shaped crack in a three dimensional problem (see for instance Ref. [1]), $a_{\mathrm{th}}$ the threshold defect size under which no evolution is possible and $\mathrm{C}, \mathrm{m}, \mathrm{n}$ are material parameters (note that $\mathrm{m}$ equals $\mathrm{n}$ in a classical Paris' law). Let us note here that we implicitly assume in our description that interactions between defects can be neglected, since the evolution law, as well as the criteria for growth and failure, only depend on the defect size and not on its environment. We also discard the possibility of nucleating new cracks during the fatigue process.

Two defect sizes are particularly importarit in this description: for a given stress the threshold size, $a_{\text {th }}$, below which the defect cannot grow, and the maximum size, $a_{\max }$, the defect can assume before leading to an overall failure of the material. Both sizes can be connected to material intrinsic parameters using a generalized stress intensity factor,

$$
\mathrm{K}=\mathrm{Y} \sigma \sqrt{a}
$$

where $Y$ depends on the shape of the modelled defect. Failure of the material is given by $K_{\max }$, whereas no propagation occurs for $K_{\text {less than }} K_{t h}$. Both quantities $K_{\max }$ and $K_{t h}$ are considered as material parameters, whereas $a_{\max }$ and $a_{\mathrm{th}}$ depend on the imposed stress through Eq.(2).

From these considerations, we can readily write down the expression of two stresses which will bound the evolution of the material under fatigue. Let us call $a_{M}$ the largest defect size present in a given sample, or volume element, subjected to a uniform stress field. Under monotonic loading, the failure will occur for a value of the stress $\sigma=\sigma_{\max }$, such that

$$
\sigma_{\max }=\frac{K_{\max }}{Y \sqrt{a_{M}}} .
$$

Whereas, for cyclic loading, if the maximum stress is smaller than a threshold $\sigma_{\mathrm{th}}$,

$$
\sigma_{\mathrm{th}}=\frac{K_{\mathrm{th}}}{\mathrm{Y} \sqrt{a_{\mathrm{M}}}}
$$

then no defect will grow _ and thus the material will not fail _ whatever the number of cycles. In the interval $\sigma_{\mathrm{th}}<\sigma<\sigma_{\mathrm{u}}$, failure will occur after a finite number of cycles. 
In the case of fatigue, the influence of the mean stress on the threshold stress can also be studied. We proposed in the evolution law to take into account the maximum stress over a cycle, i.e. the sum of the mean stress $\bar{\sigma}$ and the half amplitude stress $\Delta \sigma / 2$. Thus in a Haig's diagram, the equation of the Haig's curve is given by : $\bar{\sigma}+\Delta \sigma / 2=B$, where $B$ is a constant determined by the half amplitude stress $\sigma_{\text {th }}$ obtained with a mean stress equal to zero. This assumption is supported by experimental results [2].

The defect size distribution is supposed to be characterized by a probability density function $\mathrm{f}$. We do not consider other parameters such as the orientation, or the shape of the defects [3]. These features can be thought of being already integrated through the definition of an effective mean defect size. In the following, for the sake of simplicity, we will consider only the case of constant cyclic loadings. Generalization to more complex loadings can be done easily by integration of Eq.(1).

For cyclic loadings, function $f$ evolves with the number of cycles and with the load level $\sigma$ as parameters : $\mathrm{f}$ is denoted by $\mathrm{f}_{\mathrm{N}}(a, \sigma)$. Using evolution law $(1)$, it is easy to compute $\mathrm{f}_{\mathrm{N}}(a, \sigma)$ and to relate it to the initial distribution. Integration of (1) gives the defect size, $a(N)$, after $\mathrm{N}$ cycles, knowing the initial size $a(0)$.

$$
\begin{array}{ll}
a(N)=a(0) & \text { if } a(0)<a_{\text {th }} \\
\varphi(\sqrt{a(N)})-\varphi(\sqrt{a(0)})=C \sigma^{\mathrm{n} N} & \text { if } a(0)>a_{\text {th }}
\end{array}
$$

where the function $\varphi$ can be written

$$
\varphi(x)=\frac{\left(\mathrm{x}-\sqrt{a_{\mathrm{th}}}\right)^{1-\mathrm{m}}\left((1-\mathrm{m}) \mathrm{x}+\sqrt{a_{\mathrm{th}}}\right)}{(2-\mathrm{m})(1-\mathrm{m})}
$$

when $m \neq 1$ and $m \neq 2$. (Those two special cases have a different expression which can be written without difficulty.) It is useful to introduce a function $\psi$ such that $\alpha(0)=\psi(a(N), \sigma, N)$. $\psi$ can be computed from Eqs. ( 5 and $5^{\prime}$ ), although a closed expression cannot be written for a general value of parameter $m$. Since the evolution equation (1) is deterministic, the probability to find a defect of size $a$ after $\mathrm{N}$ cycles is equal to the probability to find initially a defect of size $\psi(a, \sigma, N)$. Since it is assumed that no new crack nucleates, $f_{N}$ can be related to $f_{0}$ by

$$
f_{N}(a, \sigma)=f_{0}(\psi(a, \sigma, N)) \frac{\partial \psi}{\partial a}
$$

where the coefficient ( $\partial \psi / \partial a)$ comes from the change of the measure (from da to d $\psi(a)$ ). 


\section{Structural analysis:_Expression of the Cumulative_Initiation_Probability}

We consider a structure $\Omega$ of volume $V$, subjected to any stress field, which can be divided into a large number of elements of volume $\mathrm{V}_{0}$. The latter being a representative volume element subjected to uniform stress fields. The cumulative initiation probability $P_{10}$ is the probability to find a defect larger than the critical defect size $a_{\max }$. Thus for monotonic loadings,.

$$
P_{10}=\int_{a_{n=}}^{\infty} f_{0}(x) d x .
$$

In the case of cyclic loading we can apply the same argument, using $f_{N}$ instead of $f_{0}$. Using relation (6), $P_{10}$ can be rewritten as :

$$
P_{I 0}=\int_{\psi\left(a_{\max }, \sigma, N\right)}^{\infty} f_{0}(x) d x
$$

where $\psi\left(a_{\max }, \sigma, N\right)$ represents the initial defect size that, after $N$ cycles and under a stress $\sigma$, reaches the critical defect size $a_{\max }$. Hence, relation (8) has a similar form as expression (7) and constitutes a generalization to cyclic loadings [3].

If the propagation phase is unstable (e.g. for brittle materials such as engineering ceramics [4]), the cumulative initiation probability also corresponds to the cumulative failure probability : relation (8) represents whence the correlation between the defect distribution and the cumulative failure probability.

Let us also note that for structures made of brittle material and submitted to cyclic loadings, relation (7) does not give a decoupling of the cumulative failure probability $P_{10}$ in a product of a function that depends only upon the load level by a function that depends only upon the number of cycles $\mathrm{N}$, as suggested in Ref. [5].

On the structural scale, the initiation occurs if one defect within the volume becomes critical. That means that if this defect reaches the critical size, $a_{\max }$, the initiation occurs. Determining the initiation at the structural scale is equivalent to finding the "weakest" link in the structure, which is expected to be a good approximation for brittle materials with a dilute density of defects. Let us also recall that we already used the assumption that the interactions between defects could be neglected during initiation, and the hypothesis of the independence of events ([6], [7]). The curmulative initiation probability $P_{I}$ of a structure $\Omega$ can be related to $P_{10}$ by : 


$$
\ln \left(1-P_{1}\right)=\frac{1}{V_{0}} \int_{\Omega} \ln \left(1-P_{10}\right) d V
$$

By means of expressions (8) and (9), a general relationship between the defect distribution and the initiation (or failure) probability of a structure $\Omega$ can be derived :

$$
\mathrm{P}_{\mathrm{I}}=1-\exp \left[\frac{1}{\mathrm{~V}_{0}} \int_{\Omega} \ln \left\{1-\int_{\psi\left(\mathrm{amax}_{\max }, \mathrm{N}\right)}^{\infty} \mathrm{f}_{0}(\mathrm{x}) \mathrm{dx}\right\} \mathrm{dV}\right] \quad \text { for cyclic loadings }
$$

For monotonic loading, the same equation holds with the substitution of $\psi\left(a_{\max }, \sigma, N\right)$ into $a_{\max }$. It should be emphasized that expression (10) also represents the cumulative failure probability if the propagation process is unstable as for engineering ceramics such as silicon nitride [4].

\section{Iso-Cumulative Initiation_Probabilities}

In the case of a given fatigue loading, the iso-cumulative initiation probabilities are given, on a structure scale, by $\mathrm{P}_{\mathrm{I}}=$ constant, thus $\mathrm{F}\left(\psi\left(a_{\max }, \sigma, N\right)\right)=$ constant where $\mathrm{F}$ is the cumulative frequency associated to function $f_{0}$, since the loading pattern is constant. This condition can simply be rewritten as :

$$
\psi\left(\mathrm{K}_{\max }^{2} / \mathrm{Y}^{2} \sigma^{2}, \sigma, N\right)=\mathrm{A}
$$

where $\mathrm{A}$ is a constant. Let us stress this important result:

The iso-probability curves in the plane $(\sigma, N),($ Wöhler diagram) are independent of the defect size distribution $\mathrm{f}_{0}$. The latter allows to quantify the value of the probability on a given curve, but does not affect its shape.

The iso-probability curves are solely determined by the evolution equation, Paris' law (1).

The number of cycles $\mathrm{N}$ corresponding to a given probability can be derived from equations ( $\left.5^{\prime}\right)$ and (11):

$$
\mathrm{N}=\frac{1}{\mathrm{C} \sigma^{\mathrm{n}}}\left\{\varphi\left(\mathrm{K}_{\max } / Y \sigma\right)-\mathrm{B}\right\}
$$


where $B$ is a constant equal to $B=\varphi(\sqrt{A})$. Expression (12) shows that, whatever the value of $m$, $\mathrm{dN} / \mathrm{d} \sigma<0$, (an increase in the number of cycles, for a given probability, implies a decrease of the load). Let us note that the result (12) does not depend upon the defect distribution.

To compare two iso-probabilities $\left(\mathrm{P}_{11}\right.$ and $\left.\mathrm{P}_{12}\right)$ in a Wobler diagram, one may study the quantity $\log \left(\mathrm{N}_{2} / \mathrm{N}_{1}\right)$ at a given load level. This ratio is given by

$$
\frac{\mathrm{N}_{2}}{\mathrm{~N}_{1}}=\frac{\varphi\left(\mathrm{K}_{\max } / \mathrm{Y} \sigma\right)-\mathrm{B}_{2}}{\varphi\left(\mathrm{K}_{\max } / \mathrm{Y} \sigma\right)-\mathrm{B}_{1}}
$$

where $B_{1}$ and $B_{2}$ are two constants $\left(B_{2}<B_{1}\right)$. Since $d\left(N_{2} / N_{1}\right) / d \sigma>0$ whatever the value of $m$, the iso-probabilities diverge with the applied stress. This result shows that the higher the load level, the larger the scatter of the time to initiation (to failure). It can also be noticed that this result is independent of the defect distribution, and of the power of $n$ in Paris' law (1).

\section{Cenclusions}

In the study of initiation processes, we have presented a unified framework for brittle failure under monotonic and cyclic loading taking into account the statistical distribution of defect within the material. In the case of materials for which the propagation process is unstable, expression (10) gives a relationship between the defect distribution and the cumulative failure probability. In fatigue, we have obtained the strikingly simple result that the iso-probability curves are independent of the initial statistical defect distribution of the material.

We acknowledge useful discussion with $R$. Billardon and D. Marquis. This study has been supported by the GRECO Geomateriaux.

\section{References}

1. R. Billardon, C. Adam and J. Lemaitre, Int. J. Solids Structures, 27 [7], p. 677 (1986)

2. C. Bathias and J.P. Baîlon, in "La fatigue des matériaux et des structures", (Maloine,

3. F. Hild and D. Marquis, C. R. Acad. Sci. Paris, II, 311, p. 573 (1990)

4. F. Hild and D. Marquis, Internal Report 107, L.M.T. Cachan, (1990)

5. Aoki and Sakata, Int. J. Fract., 16 [5], p. 459 (1980)

6. W. Weibull, J. Appl. Mec., 18 [3], p. 293 (1951) 7. A.M. Freudenthal, in "Fracture (an advanced treatrise)", Liebowitz ed., 2 [6], p. 591
(Academic Press, New York, 1968) 